\title{
Effects of Salinity on the Development of Hydroponically Grown Borage (Borago officinalis L.) Male Gametophyte
}

\author{
Firoozeh TORABI ${ }^{*}$, Ahmad MAJD ${ }^{1,2}$, Shekoofeh ENTESHARI ${ }^{3}$, \\ Saeed IRIAN ${ }^{1}$, Mohammad NABIUNI' \\ ${ }^{1}$ Kharazmi University, Department of Biology, Faculty of Science, 15719-14911, Tehran, Iran; firouzeh.torabi@yahoo.com ( ${ }^{*}$ corresponding author) \\ ${ }^{2}$ North Tehran Branch of Islamic Azad University, Department of Biology, Faculty of Science, 16679-34783, Tehran, Iran \\ ${ }^{3}$ Payame Noor University, Department of biology, 19395-4697, Tehran, Iran
}

\begin{abstract}
In this research, the effect of salinity on the development of anther in hydroponically-grown borage was studied. Plants grown on hydroponic media are rapidly and transiently stressed. The overall objective of this research was to elucidate the microscopic effects of salinity on the formation, development, and structure of anthers. Flowers, at different developmental stages, were removed, fixed in FAA, embedded in paraffin, and cut into 7-10 $\mu \mathrm{m}$ slices using a microtome. Staining was carried out with Hematoxylin-Eosine, and the developmental stages of the control and $\mathrm{NaCl}$-treated plants were compared. In control plants young anther consisted of 4 pollen sacs. Anther wall development followed the typical dicotyledonous pattern and was composed of an epidermal layer, an endothecium layer, and the tapetum. Microspore tetrads were tetrahedral. Salinity caused certain abnormalities during pollen developmental processes, such as the destruction of the anther wall and both the degeneration and production of abnormal pollen grains. A decrease in plant fecundity, which involves aborting pollen, followed by a change in resource from reproductive activities to metabolic reactions is possibly a general response to the deleterious effects of salinity.
\end{abstract}

Keywords: anther development, pollen grain, salt stress

\section{Introduction}

Borage (Borago officinalis L.) is an herbaceous annual plant from the Boraginaceae family which is used in traditional medicine. It is distributed throughout temperate areas of the world as a wild plant. Borage is cultivated in certain countries, including Iran, for the commercial production of seeds, which are used in pharmaceuticals due to their rich gamma linolenic acid content, an essential and unusual fatty acid (Naghdi Badi et al., 2009).

Plant response to salinity differs depending upon growth and developmental stage and the duration of exposure. The reproductive phase is considered to be even more sensitive than the vegetative one (Vadez et al., 2007).

While salinity stress has been extensively reviewed and several authors have studied the ecology, molecular biology, and physiology of salt-treated plants (Chong and Yun, 2007; Krasensky and Jonak, 2012; Munna, 2005; Munns and Tester, 2008; Saibo et al., 2009), emphasis has been mainly on insights gained from the experimentally accessible tissue, such as leaves and roots.

By comparison, studies on sexual reproduction are often more difficult because gamete development and fertilization are complex processes that occur during a short period of time and are predominantly hidden within flower tissue. Thus, understanding how different plants cope with stress during their reproductive (gametophytic) phase is critical for managing the future of agricultural productivity (Zinn et al., 2010).

The effects of salt stress on viability, germination ability, and pollen tube growth are documented for some plant species. Samineni et al. (2011) studied the salt sensitivity of Cicer arietinum L. at both the vegetative and reproductive phases. Their results showed that the addition of $\mathrm{NaCl}$ to an in vitro medium severely reduces pollen germination and tube growth. Pod formation in this plant is a particularly sensitive stage.

The effect of salt stress on reproduction in Arabidopsis was examined using plants grown on a hydroponic media. Salt stress inhibited microsporogenesis and stamen filament elongation. Nearly $90 \%$ of the ovules aborted when roots were incubated for $12 \mathrm{~h}$ in a hydroponic medium supplemented with $200 \mathrm{mM} \mathrm{NaCl}$ (Sun et al., 2004).

Sarhadi et al. (2012), studying the molecular mechanisms of salt tolerance during the reproductive stage of Oryza sativa L., compared anther proteomic patterns for two rice genotypes under salt stress. Their results showed that anther and pollen wall remodeling/metabolism proteins contribute to salt tolerance in rice. 
66

The developmental anatomy of stress-affected anthers gives some promising clues about the metabolic events that may be linked to the failure of pollen development (Saini, 1997). First, the formation of mature and fertile male gametophytes, which takes place inside the anther, depends on assimilates in the form of sucrose provided by the leaves (Pacini et al., 2006). Anther has a strong requirement for sugars during the microspore mother cell stage, and the maintenance of carbohydrate supply to the anthers is critical for pollen production. In addition, sucrose may function as an osmolyte in protecting pollen membranes and proteins during pollen dehydration or exposure to stress conditions such as diurnal changes and biotic or abiotic stress (Seki et al., 2007). Sucrose is the primary sugar imported into tissue, and cell wall invertase is the major enzyme responsible for sucrose cleavage in anther and pollen (Koonjul et al., 2005). Cell wall invertases are responsible for sucrose unloading, and their inhibition or down regulation would limit the provision of hexoses required for both tapetum and pollen development. Cell wall (extracellular) invertase genes, strongly expressed in the tapetum and pollen, have been identified in tomato (Lycopersicon esculentum Mill.; Proels et al., 2003), tobacco (Nicotiana tabacum L.; Goetz et al., 2001), Oryza sativa L. (Oliver et al., 2005), and Triticum spp (Koonjul et al., 2005).

Second, pollen grains are covered by lipid-derived structures essential for pollen dispersal, pollen-stigma communication, and pollen rehydration. Two types of sticky pollen coat material exist in angiosperms, both produced by the anther tapetum. Pollenkitt is the most common adhesive material present around the pollen grains of almost all angiosperms pollinated by animals, whereas tryphine seems to be restricted to Brassicaceae. Pollenkitt may play an important role in protecting pollen against environmental factors (Pacini and Hesse, 2005).

Overall, the histological examination of anther has been a useful tool for diagnosing the sensitivity of plants to salt stress. Therefore, this research was aimed at studying the microscopic effects of salinity on male gametophyte development, an important biological process in plant reproduction and survival.

\section{Materials and methods}

Seeds of Borago officinalis L. were obtained from the Pakanbazr Company in Iran, and plants were cultured on a hydroponic medium under greenhouse conditions. Seeds were surface sterilized with $5 \%(\mathrm{w} / \mathrm{v})$ sodium hypochlorite for $15 \mathrm{~min}$ and rinsed four times thoroughly with distilled water prior to being sown in plastic pots containing wellwashed river sand. They were allowed to germinate, and after 10 days, two similar seedlings, each having two leaves, were transferred to a hydroponic system for each replicate. Each replicate was a container that supplied a $1.5 \mathrm{~L}$ Long Ashton (Hewitt, 1966) nutrient solution. One week after being transferred to the hydroponic system, plants were treated with $120 \mathrm{mM}$ of $\mathrm{NaCl}$ solution. These plants were harvested after 35 days of salt-treatment. The solutions were aerated $12 \mathrm{~h}$ daily and changed on a weekly basis.

\section{Developmental studies}

Anthers, flowers, and young buds were collected from both control and treated plants for the characterization of salinity effects on developmental stages. The specimens were fixed in FAA (formaldehyde, glacial acetic acid, and 90\% ethanol, 5:5:90), stored in 70\% ethanol, dehydrated in a graded ethanol series, and embedded in $60^{\circ} \mathrm{C}$ melting point paraffin. Serial longitudinal and cross sections of buds and flowers at different stages of development were cut with most of the younger ones at $7 \mu \mathrm{m}$ but some older ones at 8 or $10 \mu \mathrm{m}$ using a Leica Rotary Microtome. The sections were stained with Hematoxylin-Eosin. In each stage of development, at least 15 flowers were studied under a light microscope (Olympus), and the differences between the control and the $\mathrm{NaCl}$ treated plants were analyzed.

\section{Scanning electron microscopy (SEM)}

Pollen grains were observed under a scanning electron microscope (SEM) to examine potential structural changes. On the day of anthesis, fresh flowers were collected early in the morning from both control and stressed plants. Samples were mounted fresh with double-stick tape without dehydration and sputter coated by physical vapor deposition (Sputter coater SCDOOS, BAL-TEC. Co, Switzerland) prior to being examined under a scanning electron microscope (KYKY-3200).

\section{Results}

Under control conditions, the borage flowers arose along scorpioid cymes. The cymes arose from the axils of the leaves at intervals along the stem. Each plant had a massive floral display, and blue flowers were organized in inflorescences (Fig. 1A). Flowering proceeded basipetally in the inflorescence, and each inflorescence developed several flowers. Flower structure consisted of a calyx made of five separate green sepals, a rotate corolla with a nectary in each of the five fused petals, and an erect cone of five black stamens each born on a filament. In $\mathrm{NaCl}$ treated plants numerous symptoms were detected, including reduced growth and an abnormal inflorescence. In addition, there was a general size reduction in flower organs, although none of the floral organs was absent (Fig. 1B).

Microsporogenesis and pollen development were studied in hermaphrodite flowers. In the control plants, the stamens initially appeared as small meristems prominent on the receptacle. The buds in early developmental stages contained anther primordia and a central ovular primodium enveloped by sepals (Fig. 2B).

In both salt-stressed and control plants, a transverse section of anther revealed four microsporangia with con- 

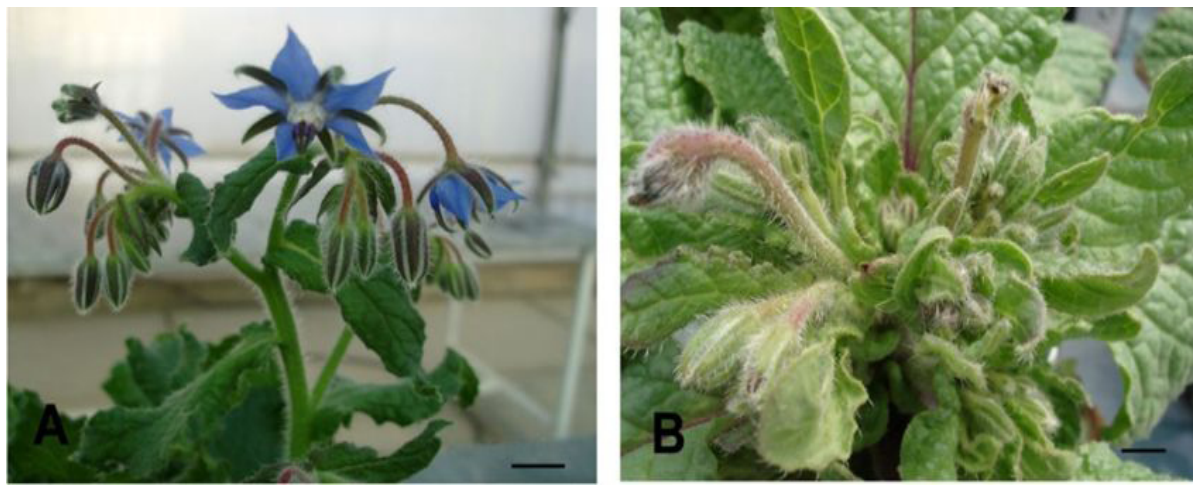

Fig. 1. Inflorescence of borage. A: Control plant B: $\mathrm{NaCl}$-treated plant. Scale bars $(10 \mathrm{~mm})$

nective tissue in the center (Fig. 2C-3A). In the control plants, each pollen sac contained peripheral cells and an archeosporial cell. As a result of an ordered series of archeosporial periclinal cell division, the undifferentiated cell layers of the wall were formed, while divisions in other directions produced sporogenous cell masses (Fig. 2D), which were not observed in the stressed plants. Following mitotic divisions in the sporogenous cell masses that fill the center of the pollen sac, microsporocytes or pollen mother cells were formed and were differentiable from the surrounding cells by their large dimensions, highly dense cytoplasm, and large and distinct nucleus (Fig. 2E and $2 \mathrm{~F}$ ). The anther wall layers showed some differences in plants under control and stress conditions. In control plants, the anther wall differentiation led to the formation of epidermis, endothecium, and tapetum, with no sign of the formation of the middle layer (Fig. 2F). Under salinity conditions, it was clear that the anthers did not grow normally; some were deformed and deteriorated (Fig. 3E). Necrotic regions in anther wall layers and abnormal pollen mother cells were observed in very young anthers (Fig. 3A and $3 \mathrm{~B}$ ). In both the control and treated plants, each pollen mother cell increased in size and formed a special wall of a callosic nature. Pollen mother cells started meiosis during microsporogenesis. Following meiosis I, two dyad nuclei in a common cytoplasm were formed without the formation of a cell plate (Fig. 2G), which was not observed in plants under salinity conditions. After meiosis II, four haploid nuclei formed and cytokinesis occurred simultaneously. Tetrahedral tetrads were visible and surrounded by a special callosic wall (Fig. $2 \mathrm{H}$ and 2I). Compared with the control, treated plants at the tetrad stage exhibited some anther loculi filled with wholly degenerated tetrads, while only a few tetrads appeared viable or normal in shape (Fig. 3C).

On the whole, tapetal cells usually reached their largest size during the tetrad formation stage. Furthermore, tapetal cells, due to their nourishing role, were the most chromatic cells compared with other cells of the anther wall. The tapetal layer was of a secretory type. By the end of meiosis, the callosic walls around these cells simultaneously started prompt degradation, and finally young microspores sepa- rated from each other. The young microspores in the unstressed control plants were normal, spherical cells with a dense cytoplasmic content and a prominent nucleus in the center (Fig. 2J and 2K). On the contrary, young microspores in the stressed plants were fewer in number, distorted in shape, and transparent, indicating a lower cytoplasmic content as a result of abnormal development (Fig. 3D). A further change in stressed plants included an unusual adhesion of microspores (Fig. 3D).

In normal plants, the growth of microspores, immediately following their release from the callosic cover, was noticeable and accompanied by hydration and vacuolization of the cytoplasm. Microspore development was completed with a single unequal mitotic division resulting in two cells with different functions and morphology, namely the vegetative and generative cells (Fig. $2 \mathrm{~N}$ ). At the same time, fiber thickening of the mechanical layer (endothecium) and xylem decoration were detectable in this layer (Fig. $2 \mathrm{~L}$ ). The tetrasporangiate anther opened by a longitudinal split, while the tapetal layer had been digested by this time (Fig. 2M).

Results of the SEM study revealed pollen grains of borage as zonocolporate with a medium size of $38 \mu \mathrm{m}$ in the equatorial view and $25.6 \mu \mathrm{m}$ in the polar view. Pollen grain shape was elliptical in the equatorial view and circular in the polar view. There were ten apertures with a $24-25 \mu \mathrm{m}$ ectoaperture length. Tectum was punctuated and densely gemmated, covered with numerous spherical granules (Fig. $4 \mathrm{~A}$ and $4 \mathrm{~B}$ ). In comparison with the control, pollen grains under salinity conditions had a smaller size of 22.5 $\mu \mathrm{m}$ in the equatorial view, with abnormalities observed on the surface (Fig. 4C and 4D). Finally, an unusual adhesion of pollens was also detected.

\section{Discussion}

Hydroponic growth allowed both the precise control and quick adjustment of the nutrient status and solute concentration. The present research investigated the developmental stages of male gametophyte in salt-stressed borage. Salt stress negatively affected the reproductive phase. These negative effects could be due to the cumula- 
68
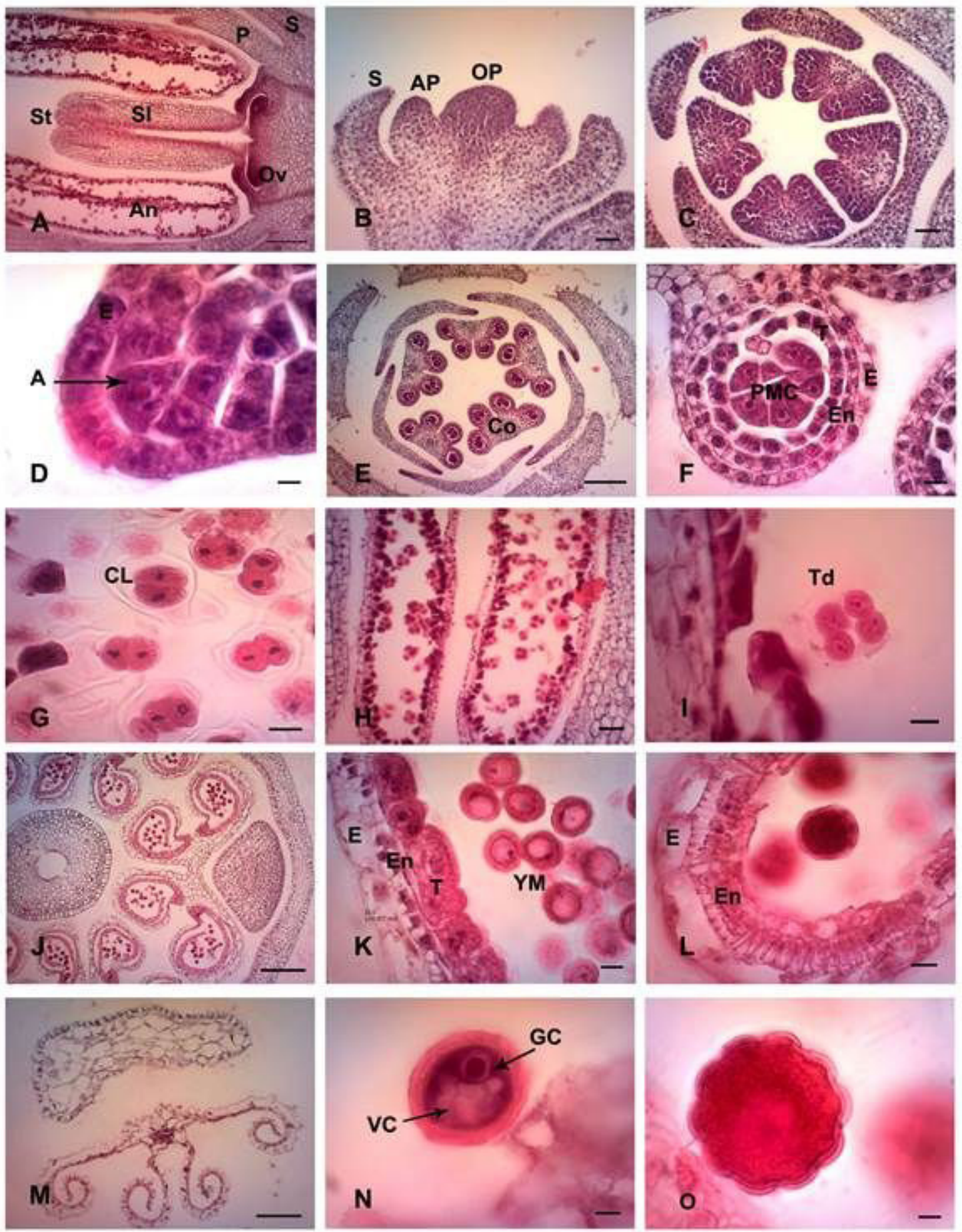

Fig. 2. Developmental stages of anther and pollen grains of Borago officinalis L.; A-Longitudinal section of the flower; B-Longitudinal section of a young bud with anther and ovular primordial-enclosed by sepals; C-Cross section of a young anther with four pollen sacs-sepals and petals; D-Cross section of a young anther with archeosporial cell; E-Cross section of a pollen sac containing pollen mother cells (PMC); F-Cross section of the anther with pollen mother cells starting meiosis; G-PMC at the dyad stage of meiosis: each PMC is surrounded by a callosic wall; H-longitudinal section of pollen sac containing tetrads resulting from meiosis: tapetal layer is of a secretary type; I-Tetrad surrounded by a callosic wall; J and K-Cross section of anther containing young microspores; LPollen sac containing mature microspores-endothecium layer with fiber ornaments are visible; M-Mature anther that is dehiscence and contains mature pollen grains; N-Mature pollen grain with vegetative and generative cells; $\mathrm{O}$-mature pollen grains from different views with ten apertures. A (Archeosporial cell); E (Epidermis); En (Endothecium); T (Tapetal layer); Co (Connective); YM (Young microspores); PMC (Pollen Mother Cells); Td (Tetrad); AP (Anther primordial); OP (Ovular primordial); Ov (Ovary); St (Stigma); VC (Vegetative Cell); GC (Generative Cell); S (Sepal); P (petal) ;An (Anther);Sl(Style);CL(Callose Wall). Scale bars $-100 \mu \mathrm{m}(\mathrm{A}, \mathrm{E}, \mathrm{J}, \mathrm{M}) ; 20 \mu \mathrm{m}(\mathrm{B}, \mathrm{C}, \mathrm{H},) ; 5 \mu \mathrm{m}(\mathrm{F}, \mathrm{G}, \mathrm{I}, \mathrm{K}, \mathrm{L}) ; 2 \mu \mathrm{m}(\mathrm{D}, \mathrm{N}, \mathrm{O})$ 

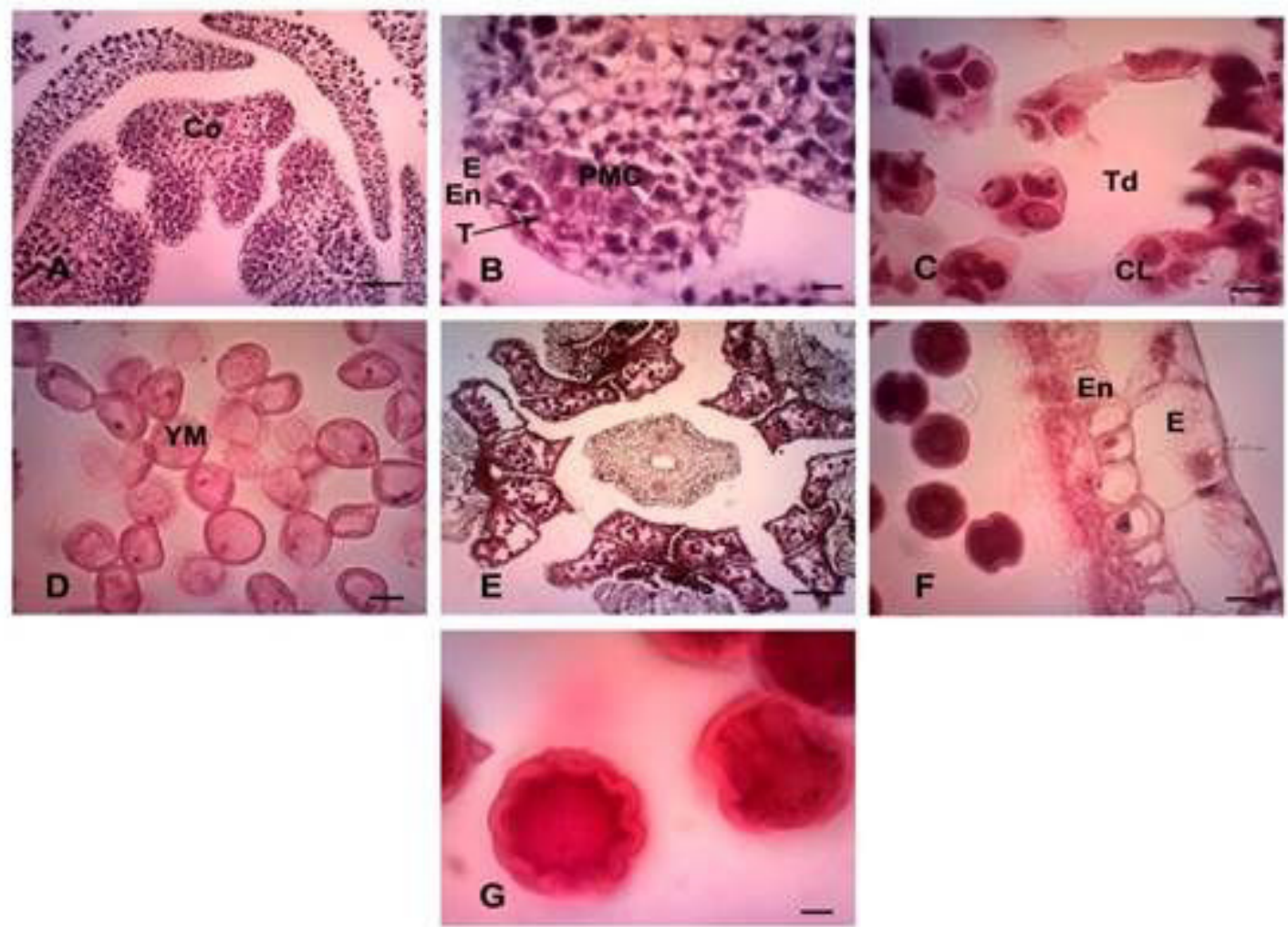

Fig. 3. Salt stress disrupted the normal development of borage pollen grains: A\& B-Cross section of a young anther that contains pollen mother cells; C-Tetrads composed of all degenerated; D-Longitudinal section of anther that contains young microspores with abnormal shape; E-Cross section of abnormal pollen sac that contains developing microspores F-Longitudinal section of anther that contains abnormal mature microspores and thick epidermis layer(show with arrow); G-Mature pollen grain. E (Epidermis); En (Endothecium); T (Tapetal layer); Co (Connective); YM (Young microspores); PMC (Pollen Mother Cells); Td (Tetrad); CL (Callose Wall). Scale bars-100 $\mu \mathrm{m}(\mathrm{E}) ; 20 \mu \mathrm{m}(\mathrm{A}) ; 5 \mu \mathrm{m}(\mathrm{B}, \mathrm{C}, \mathrm{D}, \mathrm{F}) ; 2 \mu \mathrm{m}(\mathrm{G})$
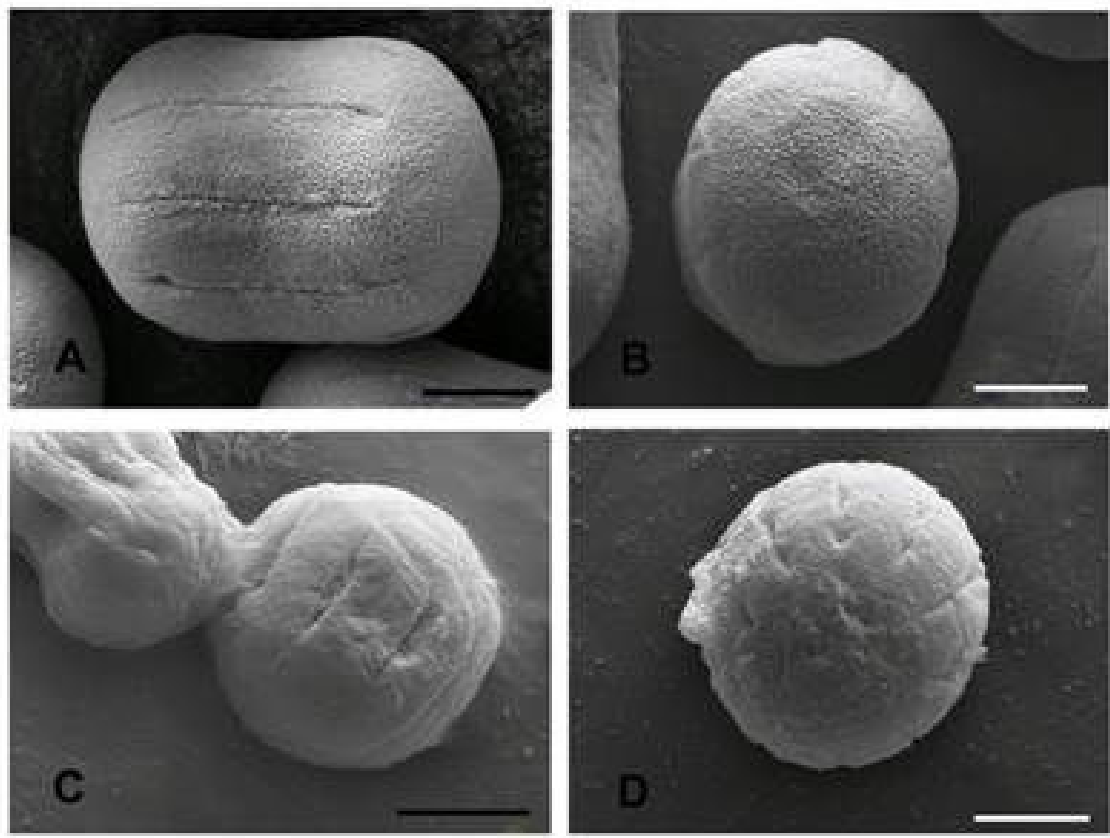

Fig. 4. Scanning electron microscopy images of pollen grains in borage. A-pollen grains of control plants in an equatorial view: three of about ten apertures are visible B-pollen grains of control plants in a polar view with ten apertures. C and D-pollen grains in a salinity condition. Scale bars- $10 \mu \mathrm{m}$ 
70

tive effect of various factors, including a reduction in the number of flowers, faulty development of pollen grains and ovules resulting in an improper fertilization and a deformed embryo, production of shrived seeds, etc.

Flower buds formed under salinity conditions were significantly reduced in size. The size reduction in floral organs could be explained by a decrease in the size of constituent cells. Our observations indicated that salt stress inhibited the elongation of cells and hence the development of buds. Similar results have been reported on the ovule and embryo sac development under environmental stress (Chehregani and Kavianpour, 2007; Chehregani et al., 2007; Rehman et al., 2004; Sulpice et al., 2003). Rehman et al. (2004) concluded that salt stress negatively affects the fertility of pollen. The sterile pollen was undersized and lacked a cytoplasm, probably due to abortion (Rehman et al., 2004).

Since salinity imposes multiple levels of stress on plants, including osmotic imbalance, malnutrition, and cellular toxicity (Zhang and Blumwald, 2001), it is difficult to identify the specific mechanisms that alter the reproductive processes of borage.

The reduction in plant fertility might be due to the increasing in ion concentration or the reduction in water potential. According to previous studies, the addition of salt to a hydroponic medium reduces the water potential of the medium and indirectly alters the root water potential (Sun et al., 2004). Sun et al. (2004) have shown that the mannitol treatment has effects similar to those of the $\mathrm{NaCl}$ treatment on ovule abortion in Arabidopsis. This finding indicates that defects in pollen development, pollination, ovule development, or seed maturation are caused primarily by water and not ionic stress.

To better understand the negative effects of osmotic stress on reproductive stages, Sulpice et al. (2003) used transgenic Arabidopsis, expressing codA gene, to increase glycine betaine. They demonstrated that salt stress inhibited the growth of anthers, pistils, and petals, and that transformation with the codA gene provided a protection against salt-stress conditions.

In salt-treated plants, the shape of the anthers changed dramatically, and anther wall differentiation did not follow the normal path. It is possible that reduced sugar delivery to the reproductive tissue upon stress-induced inhibition of photosynthesis triggers metabolic lesions leading to the failure of male gametophyte development and anther wall layer destruction. In line with this, Vesprini et al. (2002) suggested a role for cytoplasmic pollen carbohydrates in resistance against low temperature stress. In another report by Yap et al. (2008), the involvement of carbohydrates, water potential, cell wall components, and cell wall-based enzymes in regulating flower development in Dendrobium crumenatum under cold treatment was investigated. Their results indicated that carbohydrate hydrolysis, osmotic changes, and cell wall dissolution that began early in young floral buds, all regulated flower development under stress conditions (Yap et al., 2008).

Pressman et al. (2002) have also suggested that the effect of heat stress on the characteristics of tomato pollen is associated with changes in carbohydrate concentration in the developing anther. The concentration of total soluble sugars gradually increased in the anther walls and pollen grains during anther development. Exposure of the plant to high temperatures prevented the transient increase in starch concentration and led to a reduction in the concentration of soluble sugars in the anther wall and pollen grains (Pressman et al., 2002).

Salt treatment changes the shape of tetrads and young microspores. The formation of abnormal tetrads suggests that either the tetrad stage or a stage prior to tetrad formation is sensitive to salinity, a finding that is in agreement with others (Mahmoodzadeh and Kabiri, 2009). In another report, abnormal tetrads were observed when soybean flowers were subjected to a low temperature (Ohnishi et al., 2010). It appears that salt stress increases sporopollenin secretion by tepetum cells, which results in the formation of abnormal microspores.

This extra sporopollenin accumulates in several places in the anther locules. An accumulation of unpolymerized sporopollenin precursors increases the osmotic potential of the locular fluid and draws water out of the microspores, causing them to collapse. Similar results have been reported in Brassica junicea (Chauhan and Singh, 2005), Helianthus annuus L. (Tripathi and Singh, 2008), and barley (Jwell et al., 1988) on the increase in sporopollenin secretion under stress conditions.

In the final stages of pollen grain development, anther wall layers were different in control and stressed plants. In stressed plants, the epidermal cells turned thicker. The epidermis is important in protecting an organism from various environmental stresses and pathogen attack. It can therefore be concluded that the epidermal thickening is a strategy employed by plants to face stress conditions.

Both light and electron microscopic studies of pollen grains under salt stress have revealed an unusual adhesion of pollens. It appears that under salt stress, an increase in pollenkitt secretion by tapetum cells results in pollen grain adhesion. Pollenkitt in plants is known to play a protective role against water loss, and thus, an increased secretion may be a defense mechanism applied by plants against salt stress (Pacini and Hesse, 2005).

As a whole, the complex phenomenon of pollen development depends on a series of coordinated metabolic and structural changes. A dysfunction in a major metabolic pathway, such as sugar metabolism, or a dysfunction of certain cell layers could adversely affect the development of pollen grains during stress conditions. 


\section{Conclusions}

The research presented here provides basic information on describing the pollen development of borage under controlled and stress conditions. In response to the aforementioned deleterious effects of salinity, plants have evolved multiple mechanisms to overcome this stress. One of these mechanisms, a decrease in plant fecundity, involves pollen abortion, followed by a change in resource from reproductive activities into metabolic reactions aimed at increasing stress tolerance. Future studies would have to focus on the nutritional aspects of floral development in relation to salt stress, which may provide better clues to floral abortion.

\section{References}

Araus JL, Slafer GA, Royo C, Serret MD (2008). Breeding for yield potential and stress adaptation in cereals. Crit Rev Plant Sci 27:377- 412.

Chauhan SVS, Singh V(2005). Chemical induction of male sterility in Brassica juncea and its utilization for hybrid seed production. Brassica 7:117.

Chehregani A, Kavianpour F (2007). Effects of acid rain on the developmental stages of ovules and seed proteins in Bean plants (Phaseolus vulgaris L.). Am J Plant Physiol 2:367372.

Chehregani A, Lari Yazdi H, Hoseini Sh (2007). Toxic effects of diesel exhaust particles on ovules and embryonic sac development in Phaseolus vulgaris L. Middle Eastern Russ J Plant Sci Biotech 1:54-56.

Chong MS, Yun DJ (2007). Salt stress signaling. J Plant Biol 50(2):148-155.

Goetz M, Godt DE, Guivarch A, Kahmann U, Chriqui D, Roitsch T (2001). Induction of male sterility in plants by metabolic engineering of the carbohydrate supply. Proc of the Nat Acad of Sci of the USA 98:6522-6527.

Hewitt EJ (1966). Sand and water culture methods used in the study of plant nutrition. Tech. Commun. 22, Commonwealth Bureaux of Hort. and Plantation Crops, East Malling, England.

Jwell AW, Murray BG, Alloway BJ(1988). Light and electron microscopic studies on pollen development in barley grown under copper sufficient and deficient condition. Plant Cell Environ 11:273

Katerji N, VanHoorn JW, Hamdy A, Mastrorilli M (2003). Salinity effect on crop development and yield, analysis of salt tolerance according to several classification methods. Agr Water Manage 62(1):37-66.

Koonjul PK, Minhas JS, Nunes C, Sheoran S, Saini HS (2005). Selective transcriptional down-regulation of anther invertases precedes the failure of pollen development in waterstressed wheat. J Exp Bot 56:179-190.

Krasensky J, Jonak C (2012). Drought salt, and temperature stress-induced metabolic rearrangement and regulatory net- works. J Exp Bot 4:1593-1608.

Mahmoodzadeh H, Kabiri M (2009). A normal micro and megagametophyte development in Brassica napus induced by high salinity. Res J Environ Sci 5:514-521.

Munna R (2005). Genes and salt tolerance: Bring them together. New Phytol 167:645-663.

Munns R, Tester M ( 2008). Mechanisms of salinity tolerance. Annu Rev Plant Biol 59:651-681.

Naghdi Badi H, Sorooshzadeh A,Rezazadeh Sh, Sharifi M, Ghalav A, Saadat S (2009). Biochemical and antioxidant responses of borage seedlings in saline environments. J Med Plant 8:13-23.

Ohnishi S, Miyoshi T, Shirai S (2010). Low temperature stress at different flower developmental stages affects pollen development, pollination, and pod set in soybean. Environ Exp Bot 69:56-62.

Oliver SN, Van Dongen JT, Alfred SC, Mamun EA, Zhao X, Saini HS, Fernandes SF, Blanchard CL, Sutton BG, Geigenberger P, Dennis ES, Dolferus R (2005). Cold induced repression of the rice anther-specific cell wall invertase gene OSINV4 is correlated with sucrose accumulation and pollen sterility. Plant Cell Environ 28:1534-1551.

Pacini E, Guarnieri M, Nepi M (2006). Pollen carbohydrates and water content during development, presentation, and dispersal: A short review. Protoplasma 228(1-3):73-77.

Pacini E, Hesse M (2005). Pollenkitt-its composition, forms and functions. Flora 200:399-415.

Pressman E, Peet MM, Pharr DM (2002). The effect of heat stress on tomato pollen characteristics is associated with changes in carbohydrate concentration in the developing anthers. Ann Bot 90:631-636.

Proels RK, Hause B, Berger S, Roitsch T (2003). Novel mode of hormone induction of tandem tomato invertase genes in floral tissues. Plant Mol Biol 52:191-201.

Rameeh V, Cherati A, Abbaszadeh F (2012). Relationship between seed yield and shoot ions at vegetative and reproductive stages of rapeseed genotypes under saline environment. Int J Plant Res 2(3):61-64.

Rehman S, Kook HS, Lim JH, Park MR, Ko JC, Park KG, Choi JS, Kim JG, Seo YW, Kim JK, Choi KG, Yun SJ (2004). Varietal responses of pollen development to salt stress in barley. Korean J Crop Sci 49(5):407-409

Saibo NJM, Lourenço T, Oliveira MM (2009). Transcription factors and regulation of photosynthetic and related metabolism under environmental stress. Ann Bot 103:609-623.

Saini HS (1977). Effects of water stress on male gametophyte development in plants. Sex Plant Reprod 10:67-73.

Sairam RK, Tyagi A (2004). Physiology and molecular biology of salinity stress tolerance in plants. Curr Sci 86:407-421.

Samineni S, Siddique KHM, Gaur PM, Colmer TD (2011). Salt sensitivity of the vegetative and reproductive stages in chickpea (Cicer arietinum L.): Podding is a particularly sensitive stage. Environ Exp Bot 71:260-268. 
72

Sarhadi E, Mohamadi Bazargani M, Sajise AG, Abdolahi SH, Vispo NZ, Arceta M, Mohamadi Nejad GH, Sigh RK, HosseiniSalekdeh GH (2012). Proteomic analysis of rice anthers under salt stress. Plant Physiol Bioch 58:280-287.

Seki M, Umezawa T, Urano K, Shinizaki K (2007). Regulatory metabolic networks in drought stress responses. Curr Opin Plant Biol 10(3):296-302.

Sulpice R, Tsukaya H, Nonaka H, Mustardy L, Chen THH, Murata N (2003). Enhanced formation of lowers in saltstressed Arabidopsis after genetic engineering of the synthesis of glycine betaine. Plant J 36:165-176.

Sun K, Hunt K, Hauser BA (2004). Ovule abortion in Arabidopsis triggered by stress. Plant Physiol 135:2358-2367.

Tripathi SM, Singh KP (2008). Abnormal anther development and high sporopollenin synthesis in benzotriazole treated male sterile Helianthus annuus L. Ind J Exp Biol 46:71-78.

Vadez V, Krishnamurthy L, Serraj R,Gaur PM, Upadhyaya HD, Hoisington DA, Varshney RK, Turner NC, Siddique KHM (2007). Large variation in salinity tolerance in chickpea is explained by differences in sensitivity at the reproductive stage. Field Crops Res 104:123-129.
Vesprini JL, Nepi M, Cresti L, Guarnieri M, Pacini E (2002). Changes in cytoplasmic carbohydrate content during Helleborus pollen presentation. Grana 41(1):16-20.

Yap YM, Loh CS, Ong BL (2008). Regulation of flower development in Dendrobium crumenatum by changes in carbohydrate contents, water status and cell wall metabolism. Sci Hortic 119:59-66.

Yousefi N, Chehregani A, Malayeri B, Lorestani B, Cheraghi M (2011). Investigating the effect of heavy metals on developmental stages of anther and pollen in Chenopodium botrys L. (Chenopodiaceae). Biol Trace Elem Res 140(3):368-376.

Zhang HX, Blumwald E (2001). Transgenic salt-tolerant tomato plants accumulate salt in foliage but not in fruit. Nat Biotech 19:765-768.

Zhu JK (2001). Plant salt tolerance. Trends Plant Sci 6: 66-71.

Zinn KE, Tunc-Ozdemir M, Harper JF (2010). Temperature stress and plant sexual reproduction: uncovering the weakest links. J Exp Bot 61(7):1959-1968. 